\title{
Postthrombotic syndrome
}

\section{Ahmed Kayssi MD MSc, Graham Roche-Nagle MD MBA}

\section{Deep vein thrombosis leads to postthrombotic syndrome in many patients}

Postthrombotic syndrome is a chronic but preventable condition that leads to limb pain, swelling, skin discolouration and ulceration, and rash after deep vein thrombosis (DVT) (Figure 1). These signs and symptoms are seen at 10 years' follow-up in up to $56 \%$ of patients who have had DVT. ${ }^{1}$

Patients with postthrombotic syndrome can undergo a deterioration in their quality of life

Kahn and colleagues ${ }^{3}$ reported a significant decrease in disease-specific quality of life in patients with DVT who subsequently had postthrombotic syndrome compared with patients with DVT in whom the syndrome did not develop. Furthermore, patients with severe postthrombotic syndrome had a considerably lower quality of life than patients with mild or moderate forms of the syndrome. ${ }^{3}$

CMAJ invites submissions to "Five things to know about ..." Submit manuscripts online at http://mc.manuscriptcentral .com/cmaj

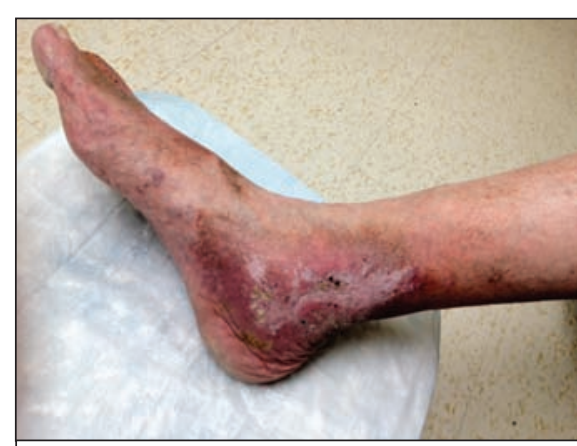

Figure 1: Postthrombotic syndrome in a 67-year-old man with a remote history of iliofemoral deep vein thromobosis that was not initially managed with compression stockings.
Preventive measures include using compression stockings and taking low-molecular-weight heparin for at least 3 months after DVT is diagnosed

A Cochrane review ${ }^{4}$ reported that compression stockings (30-40 $\mathrm{mm} \mathrm{Hg}$ ) used early after the diagnosis of DVT were associated with a $69 \%$ reduction in the odds of postthrombotic syndrome developing and a $61 \%$ reduction in the odds of severe postthrombotic syndrome. However, a recently concluded trial did not show a benefit to using external compression stockings as a preventive measure. ${ }^{5}$ A systematic review showed that long-term treatment with low-molecular weight heparin after DVT resulted in a lower incidence of posthrombotic syndrome than treatment with anticoagulants administered orally. ${ }^{6}$ There is currently no evidence from randomized controlled trials to support the role of thrombolysis in preventing postthrombotic syndrome.
The pathophysiology of postthrombotic syndrome is unclear

This syndrome is thought to be a consequence of chronic venous obstruction, venous insufficiency, increased exposure to inflammatory mediators and reduced mobility in patients who have had DVT, leading to valvular insufficiency and inadequate venous circulation. ${ }^{2}$ Risk factors for the syndrome include older age, obesity, male sex, iliofemoral (proximal) DVT, recurrent ipsilateral DVT, previous or primary venous insufficiency, and elevated D-dimer levels after withdrawal of anticoagulant agents. ${ }^{2}$

Compression stockings and exercise therapy are first-line treatments for the symptoms of postthrombotic syndrome?

There is limited evidence to support the use of pentoxifylline or horse chestnut seed extract to improve symptoms of chronic venous insufficiency in patients with severe postthrombotic syndrome. ${ }^{7}$ Surgical intervention with endovascular stent placement or endovenectomy should only be considered when medical management fails. $^{7}$

For references, please see Appendix 1, available at www.cmaj.ca/lookup/suppl /doi:10.1503/cmaj.130085/-/DC1

Competing interests: None declared.

This article has been peer reviewed.

Affiliations: The Division of Vascular Surgery, University of Toronto, Toronto, Ont.

Correspondence to: Ahmed Kayssi, ahmed .kayssi@mail.utoronto.ca

CMAJ 2014. DOI:10.1503/cmaj.130085 